\title{
Role of Sulfur as a Reducing Agent for the Transition Metals Incorporated into Lithium Silicate Glass
}

\author{
M. Y. Hassaan,,$^{1, *}$ M. M. El-Desoky, ${ }^{2}$ M. G. Moustafa, ${ }^{1}$ Y. lida, ${ }^{3}$ S. Kubuki, ${ }^{3}$ T. Nishida ${ }^{4}$
}

\footnotetext{
Physics Department, Faculty of Science, Al-Azhar University, Nasr City, 11884, Cairo, Egypt

2 Physics Department, Faculty of Science, Suez University, Suez, Egypt

3 Department of Chemistry, Graduate School of Science and Engineering, Tokyo Metropolitan University, Minami-Osawa 1-1, Hachi-Oji, Tokyo 192-0397, Japan

4 Department of Biological and Environmental Chemistry, Faculty of Human-Oriented Science and Engineering, Kinki University, lizuka, Fukuoka 820-8555, Japan

* Corresponding author's e-mail address: myhassaan@yahoo.com
}

RECEIVED: November 11, 2015 * REVISED: December 26, 2015 * ACCEPTED: December 28, 2015

THIS PAPER IS DEDICATED TO DR. SVETOZAR MUSIĆ ON THE OCCASION OF HIS 70 ${ }^{\mathrm{TH}}$ BIRTHDAY

\begin{abstract}
Li}_{2} \mathrm{O} \cdot 0.25 \mathrm{Fe}_{2} \mathrm{O}_{3} \cdot 0.25 \mathrm{NiO} \cdot 1.5 \mathrm{SiO}_{2}$ glass was prepared with and without 5 wt \% sulfur $(\mathrm{S})$ while melting the mixture of the starting materials at $1350^{\circ} \mathrm{C}$ for $1 \mathrm{~h}$ in air. A part of the as-prepared glass was heat treated for $1 \mathrm{~h}$ near its crystallization temperature $\left(T_{c}\right)$ as determined from differential thermal analysis. Each glass was also investigated by means of Mössbauer spectroscopy, X-ray diffraction, FTIR, and DC conductivity. The Mössbauer spectra showed ionic $\mathrm{Fe}^{2+}$ and $\mathrm{Fe}^{3+}$ species in the glass as well as in the precipitated phase obtained after heat treatment. XRD patterns demonstrated the glassy phase formation in the as-quenched samples irrespective of the presence of sulfur. The heat treated samples showed different precipitated phases containing iron particles of nanometer size. The electric conductivity measurements showed that sulfur-doped samples had high values of $(\sigma)$ probably because of small polaron hopping between $\mathrm{Fe}^{2+}$ and $\mathrm{Fe}^{3+}$.
\end{abstract}

Keywords: Mössbauer spectroscopy, electrical conductivity, sulfur, heat treatment.

\section{INTRODUCTION}

ITHIUM silicate glass and related ceramic have important applications such as heat-resistant glasses, glass fiber, optical glass, bioglass and bioglass-ceramic. ${ }^{[1-2]}$ Glass-ceramics are produced by controlled heat treatment of glass at temperatures near its $T_{\mathrm{c}}$. If the heat treatment time is short (e.g., less than $1 \mathrm{~h}$ ), the size of crystalline particles is expected to be of nanometer size, and provides interesting physical properties. ${ }^{[3-4]}$ Transition metal (TM) ions introduced in the glass matrix improve the physicochemical properties of glass and glass-ceramics. These ions improve the electrical conduction due to electron hopping from the lower valence state to the higher state (e.g. from $\mathrm{Fe}^{2+}$ to $\left.\mathrm{Fe}^{3+}\right)$. [5]

Recently, much attention has been paid to the development of fast-ion conductors of glass and glassceramics. Li-ion batteries (LIB) are the most popular source for different modern portable electronic devices. ${ }^{[6-8]}$ Lithium silicate glass was found to be usable as fast-ionic conductor even at low temperatures, because of its high

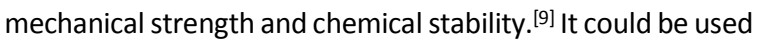
for ceramic-metal sealing and for dental restoration. ${ }^{[10-11]}$

In the present study, we investigated the dc conductivity of $\mathrm{Li}_{2} \mathrm{O} \cdot 0.25 \mathrm{Fe}_{2} \mathrm{O}_{3} \cdot 0.25 \mathrm{NiO} \cdot 1.5 \mathrm{SiO}_{2}$ glass and its glass-ceramics, in addition to Mössbauer, DTA, IR, density and XRD measurements. Since sulfur is a reducing agent, we added it to the reagent mixture to control the ionic states of $\mathrm{Ni}$ and $\mathrm{Fe}$ to facilitate the electronic conduction beside the ionic one in the glass and glass-ceramic samples.

\section{EXPERIMENTAL}

Glass samples of the composition $\mathrm{Li}_{2} \mathrm{O} \cdot 0.25 \mathrm{Fe}_{2} \mathrm{O}_{3} \cdot 0.25 \mathrm{NiO}$. $1.5 \mathrm{SiO}_{2}$ (in $\mathrm{mol} \%$ ) with and without $5 \mathrm{wt} \%$ of sulfur (S) were prepared by melt-quenching method in a platinum crucible 
at $1350{ }^{\circ} \mathrm{C}$ for $1 \mathrm{~h}$ in air using an electric furnace. The melt was quenched on a copper plate and yielded a glass plate of $1 \mathrm{~mm}$ thickness. Heat treatment was conducted for $1 \mathrm{~h}$ at $550^{\circ} \mathrm{C}$, being close to its crystallization temperature $\left(T_{\mathrm{c}}\right)$ as obtained from DTA (Shimadzu). The bulk densities were measured at room temperature using Archimedes method with carbon tetrachloride as the immersing liquid $(r=1.593$ $\mathrm{g} \mathrm{cm}^{-3}$ ). XRD measurements of glass and heat-treated samples were conducted using [Rigaku RINT 2100] with $\mathrm{Cu} K_{\alpha}(0.1541 \mathrm{~nm})$ radiation. The maximum current and voltage were $300 \mathrm{~mA}$ and $50 \mathrm{kV}$, respectively. FT-IR spectra were recorded at room temperature by standard $\mathrm{KBr}$ pellet method using computerized FT-IR spectrophotometer [JASCO FT-IR-300E] in the range $\left(400-4000 \mathrm{~cm}^{-1}\right)$.

The DC electrical conductivity for glass and glassceramics were measured by means of two-probe method, which is appropriate for high resistance materials. Polished surface of each sample was coated with silver paste, and two polished cleaned copper electrodes was attached to the coated area. A Pico-ammeter 760 was used to collect the $D C$ data over the temperature range of $300-550 \mathrm{~K}$. The sample temperature was measured by a chromel-alumel type thermocouple which was placed at a position to the sample as close as possible. The Mössbauer spectra were recorded at room temperature by a constant acceleration method with Wissel MDU-1200, connected to a digital function generator (Wissel DFG-1000). A source of ${ }^{57} \mathrm{Co}(\mathrm{Rh})$ of $925 \mathrm{MBq}$ and $\alpha$-Fe foil were used as a source and a reference, respectively. Mössbauer spectra were analyzed assuming a Lorentzian peak shape using the fitting program Mösswinn 3.0i XP.

\section{RESULTS AND DISCUSSION}

\section{DTA}

DTA was used to determine the characteristic temperatures of materials. Fig. 1 shows the DTA curve of the as-quenched glass with a composition of $\mathrm{Li}_{2} \mathrm{O} \cdot 0.25 \mathrm{Fe}_{2} \mathrm{O}_{3} \cdot 0.25 \mathrm{NiO} \cdot 1.5 \mathrm{SiO}_{2}$ containing 5 wt $\%$ of sulfur. Glass formation was confirmed from the glass transition temperature $\left(T_{\mathrm{g}}\right)$ observed at $458{ }^{\circ} \mathrm{C}$, and successive three exothermic peaks corresponding to crystallization temperatures $\left(T_{\mathrm{c} 1}, T_{\mathrm{c} 2}, T_{\mathrm{c} 3}\right)$ observed at 597, 664 and $736{ }^{\circ} \mathrm{C}$, respectively, followed by endothermic effect due to melting $\left(T_{\mathrm{m}}\right)$ at $1015^{\circ} \mathrm{C}$.

\section{Density}

Densities of the as-quenched glass sample with and without $5 \mathrm{wt} \%$ sulfur are listed in Table 1, together with those for HT samples. Table 1 show that the density of S-free sample is greater than that of S-doped sample. The decrease in the density after sulfur addition indicates the reduced rigidity

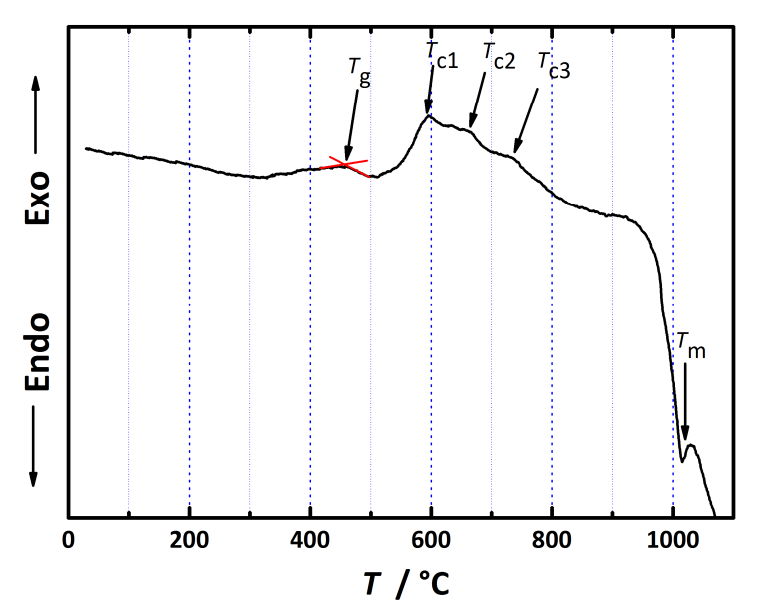

Figure 1. DTA curve of as-quenched glass with a composition $\mathrm{Li}_{2} \mathrm{O} \cdot 0.25 \mathrm{Fe}_{2} \mathrm{O}_{3} \cdot 0.25 \mathrm{NiO} \cdot 1.5 \mathrm{SiO}_{2}$ plus 5 wt \% sulfur.

of the glass matrix; there is a weakening of the structure, which will be favorable for the higher mobility of cations and consequently higher electrical conductivity (see section "Electrical Conductivity"). On the other hand, density of HT samples was greater than that of corresponding asquenched glasses. The increase in the density of HT samples may be due to the rearrangement of ions causing structural changes to form glass-ceramics, i.e. the ions closely packed than in glass. ${ }^{[4]}$

\section{X-ray Diffraction (XRD)}

XRD of the glass samples and its HT samples was measured using $\mathrm{Cu} K_{\alpha}$ radiation at room temperature to examine their amorphous and/or crystalline nature. Fig. 2 shows XRD pattern of $\mathrm{Li}_{2} \mathrm{O} \cdot 0.25 \mathrm{Fe}_{2} \mathrm{O}_{3} \cdot 0.25 \mathrm{NiO} \cdot 1.5 \mathrm{SiO}_{2}$ glass with $5 \mathrm{wt} \%$ sulfur (bottom), and those of $\mathrm{HT}$ samples with and without sulfur. In the case of as-quenched glasses, as shown in Fig. 2 (bottom), a representative hallo was observed at around $2 \vartheta=20-35$ degrees with no diffraction peaks, confirming the glass formation. In the case HT-samples, some sharp peaks were observed being ascribed to $\mathrm{LiFeSi}_{2} \mathrm{O}_{6}$ (JCPDS card 71-1064) with a structure close to monoclinic, $\mathrm{Fe}_{21.32} \mathrm{O}_{34}$ (JCPDS card 802186) with a structure close to tetragonal and $\mathrm{Fe}_{2} \mathrm{O}_{3}$ (JCPDS card 89-0596) with a structure close to rhombohedral.

Table 1. Densities of $\mathrm{Li}_{2} \mathrm{O} \cdot 0.25 \mathrm{Fe}_{2} \mathrm{O}_{3} \cdot 0.25 \mathrm{NiO} \cdot 1.5 \mathrm{SiO}_{2}$ glasses with and without sulfur (S) and those of corresponding HT samples.

\begin{tabular}{ccc}
\hline $\begin{array}{c}\text { Samples with S / } \\
\text { wt } \%\end{array}$ & $\begin{array}{c}\text { Density of glass } \\
\text { samples } / \mathrm{g} \mathrm{cm}^{-3}\end{array}$ & $\begin{array}{c}\text { Density of HT } \\
\text { samples } / \mathrm{g} \mathrm{cm}^{-3}\end{array}$ \\
\hline 0 & 2.86 & 2.89 \\
5 & 2.76 & 2.81 \\
\hline
\end{tabular}




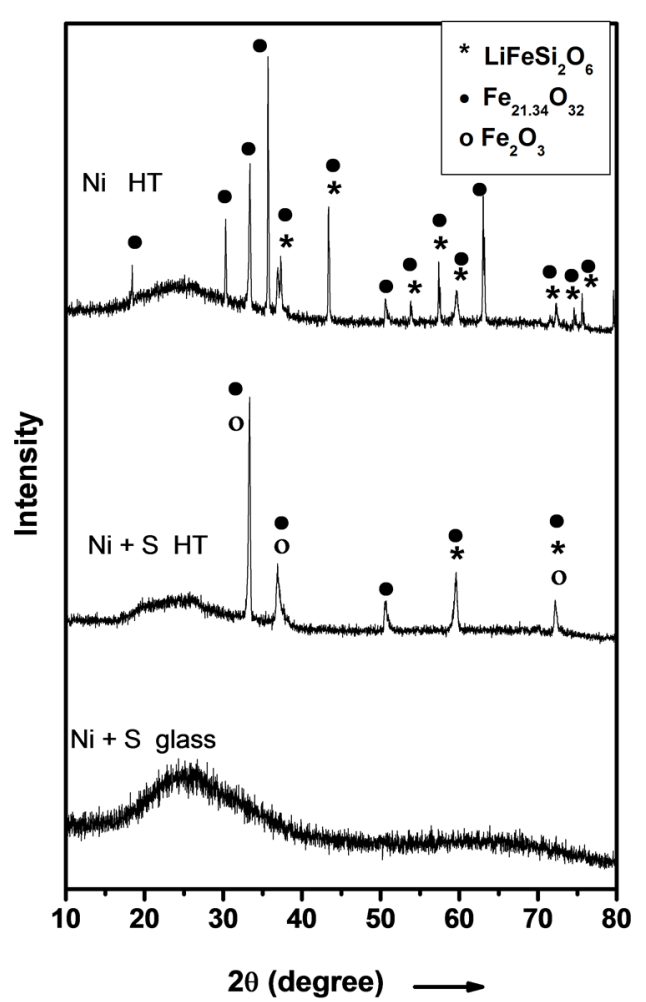

Figure 2. XRD patterns of $\mathrm{Li}_{2} \mathrm{O} \cdot 0.25 \mathrm{Fe}_{2} \mathrm{O}_{3} \cdot 0.25 \mathrm{NiO} \cdot 1.5 \mathrm{SiO}_{2}$ glasses with 5 wt \% sulfur (S) and $\mathrm{HT}$ samples with and without S.

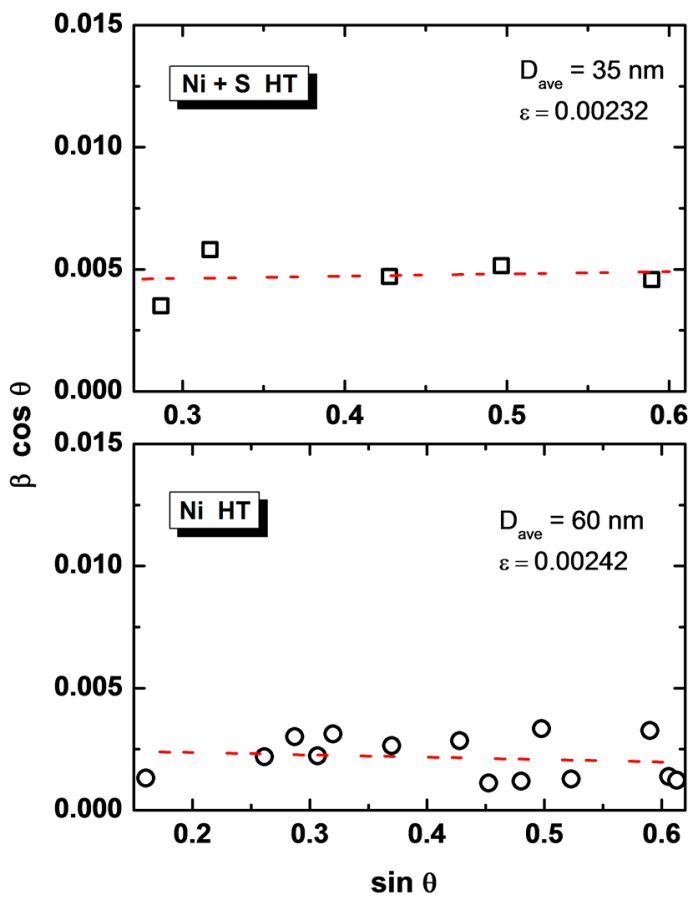

Figure 3. $\mathrm{W}$-H plot for $\mathrm{Li}_{2} \mathrm{O} \cdot 0.25 \mathrm{Fe}_{2} \mathrm{O}_{3} \cdot 0.25 \mathrm{NiO} \cdot 1.5 \mathrm{SiO}_{2}$ samples (HT) with and without $5 \mathrm{wt} \%$ sulfur (S).
Using XRD data, the average crystallite size was calculated from Williamson-Hall (W-H) plot between $B \cos \vartheta$ and $\sin \vartheta$, as given in Fig. 3. ${ }^{4,12]}$ The Williamson-Hall equation is

$$
B \cos \vartheta=\frac{c \lambda}{D_{\text {ave }}}+4 \varepsilon \sin \vartheta
$$

where $B$ is the fullwidth at half maximum (FWHM), $\vartheta$ is the Bragg angle, $c$ the correction factor $(c \approx 1), D_{\text {ave }}$ the average crystallite size, $\lambda$ the wavelength of $\mathrm{X}$-ray, $\varepsilon$ the lattice strain. It is observed that the average crystallite size of $\mathrm{S}$ free sample is greater than that of S-doped one.

\section{Fourier-Transform Infrared Spectroscopy}

FTIR spectroscopy is an important tool for the characterization of glass sample. Figure 4 shows FTIR absorption spectra of HT samples of S-doped and S-free glasses. In the case of S-free glass, the broad band observed at $\sim 485 \mathrm{~cm}^{-1}$ was assigned to $\mathrm{Si}-\mathrm{O}-\mathrm{Si}$ bending vibration of $\mathrm{SiO}_{4}$ tetrahedra. ${ }^{[13-15]}$ After $\mathrm{HT}$, this broad band slightly shifted to a high wavenumber region of $493 \mathrm{~cm}^{-1}$. In the case of Sdoped glass, the broad band observed at $\sim 478 \mathrm{~cm}^{-1}$ was assigned to $\mathrm{Si}-\mathrm{O}-\mathrm{Si}$ bending vibration in $\mathrm{SiO}_{4}$ tetrahedra. This broad band shifted to $485 \mathrm{~cm}^{-1}$ after HT.

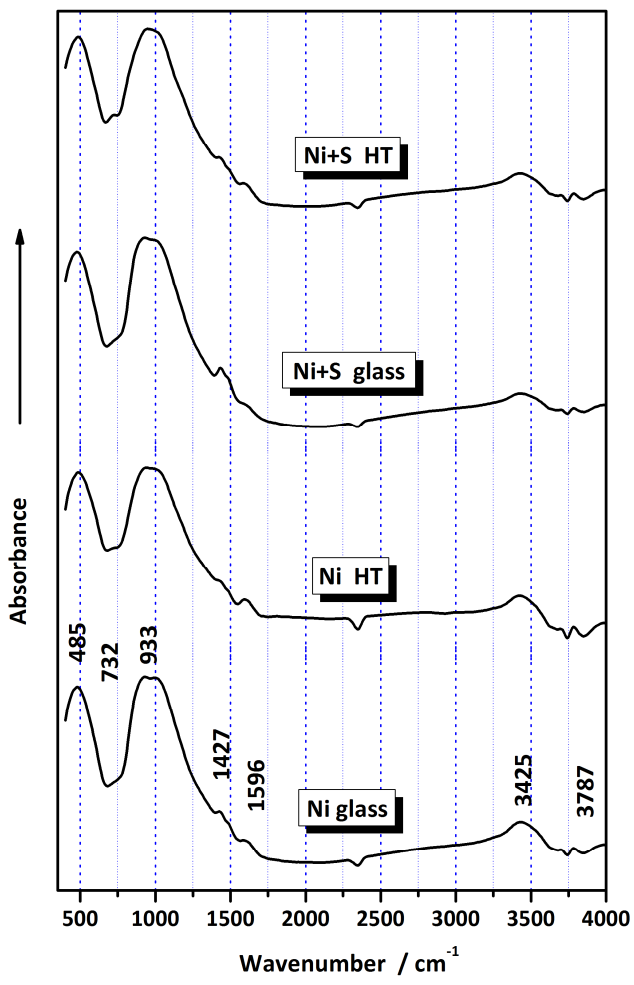

Figure 4. FTIR absorption spectra of $\mathrm{Li}_{2} \mathrm{O} \cdot 0.25 \mathrm{Fe}_{2} \mathrm{O}_{3}$. $0.25 \mathrm{NiO} \cdot 1.5 \mathrm{SiO}_{2}$ glasses with and without $5 \mathrm{wt} \%$ sulfur (S), together with the spectrum of HT sample (S-free). 
In the case of S-free glass, a weak shoulder at $732 \mathrm{~cm}^{-1}$, attributed to the symmetric stretching vibration of $\mathrm{Si}-\mathrm{O}-\mathrm{Si}$ bridging bonds, was observed at the same position after HT. ${ }^{[16]}$ After the sulfur addition, this shoulder was observed at almost the same position. The bands appearing in the region of $933-995 \mathrm{~cm}^{-1}$ were attributed to the asymmetric stretching vibrations of $\mathrm{Si}-\mathrm{O}-\mathrm{Si}$ bridging bonds. ${ }^{[16]}$ The band observed at $1427 \mathrm{~cm}^{-1}$ was assigned to the deformation vibration of $\mathrm{H}-\mathrm{O}-\mathrm{H}$ groups in the structure of glass or surface adsorbed water. ${ }^{[17]}$ The band appearing at $1596 \mathrm{~cm}^{-1}$ will be due to the deformation vibration mode of the $\mathrm{H}_{2} \mathrm{O} \cdot{ }^{[4,18]}$ The band observed at around $3425 \mathrm{~cm}^{-1}$ is ascribed to the stretching vibration of $\mathrm{OH}$ group. ${ }^{[4,18]}$

\section{Mössbauer Spectroscopy}

Figure 5 shows Mössbauer spectra measured at room temperature. In the case of S-free samples, Mössbauer spectra exhibited one doublet of $\mathrm{Fe}^{3+}$ tetrahedral $\left(T_{\mathrm{d}}\right)$ in both the as-quenched and HT samples. In case of S-doped glass, the above doublet appeared with another weak doublet due to $\mathrm{Fe}^{2+}\left(O_{\mathrm{h}}\right)$. In the sample doped sulfur, peaks due to $\mathrm{Fe}_{2} \mathrm{O}_{3}$ precipitated observed as a result of heat treatment, as was confirmed the XRD study. Mössbauer parameters are summarized in Table 2.

\section{Electrical Conductivity}

Figure 6 shows a semiconducting temperature dependence of the electrical conductivity $\sigma(T)$, for S-free and S-doped glasses and that for HT samples, which are described by Mott equation (2). ${ }^{[5,19]}$

$$
\sigma T=\sigma_{0} \exp (-W / k T)
$$

where $\sigma_{0}$ is a pre-exponential factor as discussed below. The activation energy $(W)$ and pre-exponential factor $\left(\sigma_{0}\right)$ were obtained from the least square fits of the data. The straight line nature of the Mott-type plot indicates that the conduction is thermally activated, as often found in several semiconductors. Value of $W$ reflecting the thermal energy required to promote the polaron hopping from one site to another was calculated to be $0.51-0.59 \mathrm{eV}$. Values of $\sigma$ and $W$ obtained at $408 \mathrm{~K}$ are listed in Table 3.

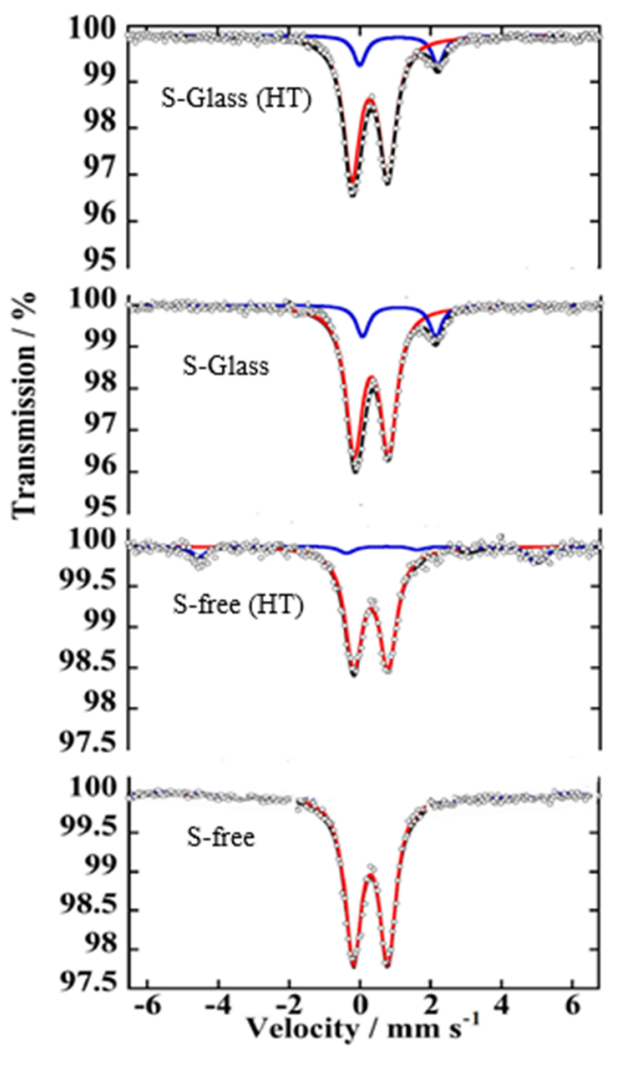

Figure 5. RT Mössbauer spectra of $\mathrm{Li}_{2} \mathrm{O} \cdot 0.25 \mathrm{Fe}_{2} \mathrm{O}_{3} \cdot 0.25 \mathrm{NiO}$. $1.5 \mathrm{SiO}_{2}$ glasses with and without $5 \mathrm{wt} \%$ sulfur (S), and those of HT samples.

In Fig. 6 and Table 3 are shown dc conductivities of Sdoped and S-free glasses, together with those for HT samples measured at a fixed temperature ( $408 \mathrm{~K})$. They indicate that the conductivity of S-doped glass samples is higher than that of S-free glass. This may be due to the presence of $\mathrm{Fe}^{2+}$ ions in $\mathrm{S}$ - doped glass and its $\mathrm{HT}$ sample, as confirmed by the Mössbauer study. It is considered that sulfur atoms acted as a reducing agent in S-doped glass, which caused the reduction of $\mathrm{Fe}^{3+}$ to $\mathrm{Fe}^{2+}$ ions. ${ }^{[20]}$ When the glass was heat treated at $550{ }^{\circ} \mathrm{C}$ for $1 \mathrm{~h}$, randomly dispersed nanocrystals were formed in the glass matrix. As a result, the electrical conductivity was one order of

Table 2. RT-Mössbauer parameters of $\mathrm{Li}_{2} \mathrm{O} \cdot 0.25 \mathrm{Fe}_{2} \mathrm{O}_{3} \cdot 0.25 \mathrm{NiO} \cdot 1.5 \mathrm{SiO}_{2}$ glasses with and without 5 wt $\%$ sulfur (S) and those for HT samples.

\begin{tabular}{ccccccccc}
\hline \multirow{2}{*}{ Samples } & \multicolumn{4}{c}{$\mathrm{Fe}^{3+}\left(T_{\mathrm{d}}\right)$} \\
\cline { 2 - 9 } & $\mathrm{IS} / \mathrm{mm} \mathrm{s}^{-1}$ & $\mathrm{QS} / \mathrm{mm} \mathrm{s}^{-1}$ & $\mathrm{LW} / \mathrm{mm} \mathrm{s}^{-1}$ & $\mathrm{~A} / \%$ & $\mathrm{IS} / \mathrm{mm} \mathrm{s}^{-1}$ & $\mathrm{QS} / \mathrm{mm} \mathrm{s}^{-1}$ & $\mathrm{LW} / \mathrm{mm} \mathrm{s}^{-1}$ & $\mathrm{~A} / \%$ \\
\hline S-free Glass & 0.30 & 0.97 & 0.56 & 100 & - & - & - & - \\
S-free Glass (HT) & 0.31 & 0.96 & 0.59 & 100 & - & - & - & - \\
5 wt \% S- Glass & 0.30 & 0.96 & 0.56 & 85.7 & 1.08 & 2.066 & 0.42 & 14.3 \\
5 wt \% S-Glass (HT) & 0.28 & 1.01 & 0.56 & 86.0 & 1.10 & 2.20 & 0.42 & 14.0 \\
\hline
\end{tabular}




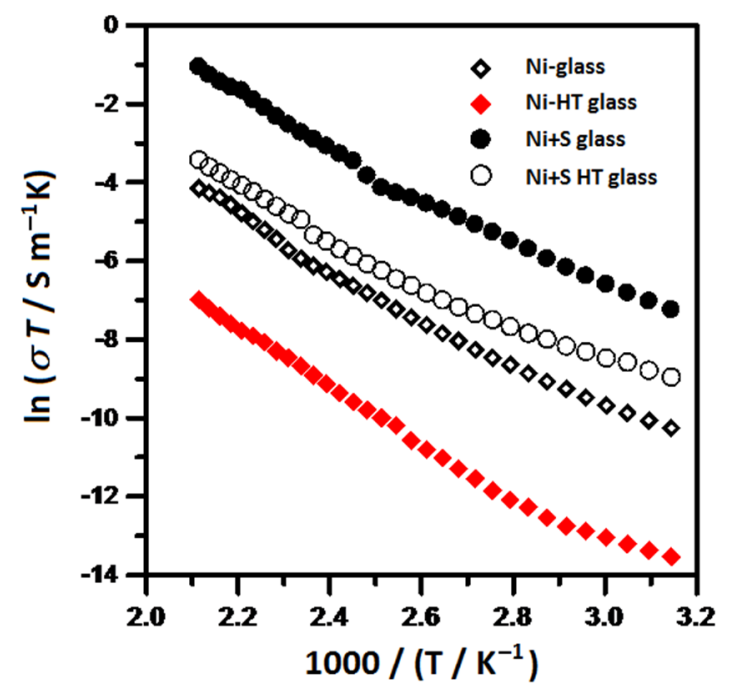

Figure 6. Temperature dependence of dc conductivity $(\sigma T)$ for the glasses with and without $S$ and their $(H T)$ samples.

magnitude smaller than that of as-quenched glass. It is speculated that nanocrystals produce ion-blocking effect imposed in the lithium ions in the glass matrix. This blocking effect was discussed for the oxygen-conducting nanomaterials. ${ }^{[21]}$ In our samples, the blocking effect on the oxygen ions might be caused by grain boundaries or pores that formed in the samples after heat treatment.

The concentration of iron ions $N\left(\mathrm{~cm}^{-3}\right)$ may be evaluated using the density by the relation:

$$
N=d p N_{\mathrm{A}} / A_{\mathrm{W}}
$$

where $d$ is the density of the sample, as evaluated above and presented in Table 1, $p$ is the weight percentage of atoms, $N_{\mathrm{A}}$ is the Avogadro's number and $A_{\mathrm{W}}$ the molecular weight. While the relationship between $N$ and the mean distance $R$ between iron ions is generally described as:

$$
R=(1 / N)^{1 / 3}
$$

The calculated values of $R$ and $N$ are summarized in Table 3.

Table 3. Physical properties for the glasses with and without $\mathrm{S}$ and also for heat-treated samples, measured at $408 \mathrm{~K}$.

\begin{tabular}{ccccc}
\hline Samples & $\begin{array}{c}\ln (\sigma T / \\
\left.\mathrm{S} \mathrm{m}^{-1} \mathrm{~K}\right)\end{array}$ & $W / \mathrm{eV}$ & $\begin{array}{c}10^{22} \mathrm{~N} / \\
\mathrm{cm}^{-3}\end{array}$ & $R / \mathrm{nm}$ \\
\hline S-free glass & -6.63 & 0.52 & 0.88 & 0.484 \\
S-free glass (HT) & -9.59 & 0.59 & 0.90 & 0.480 \\
S-doped glass & -3.45 & 0.51 & 0.85 & 0.489 \\
S-doped glass (HT) & -5.87 & 0.53 & 0.87 & 0.486 \\
\hline
\end{tabular}

In the range of measurements (Table 3 ), $W$ depends on the site-to-site distance $R$. These results show that there is a correlation between $W$ and $\mathrm{R}$ between iron ions. The effect dependence of $\sigma$ on the present samples can be explained by the changes of the distance between the iron ions, $R$. It is concluded, therefore, that the conduction between iron ions depends strongly on $R$ which is important to the conduction mechanism of our samples. This agrees with the results obtained recently by El-Desoky. ${ }^{[22]}$

\section{CONCLUSION}

XRD patterns confirmed the glassy and precipitated nature of as-quenched glass samples before and after heat treatment, respectively. Particle size of the precipitated nanocrystals was estimated after the HT process. Density of sulfur-free glass sample was higher than that of sulfurdoped sample. Decrease of the density in the sulfurcontaining glass sample was consistent with the reduced rigidity. Mössbauer spectra of S-free samples showed one doublet due to tetrahedral $\mathrm{Fe}^{3+}$ in both the as-quenched and HT samples. In S-doped samples, a weak doublet due to $\mathrm{Fe}^{2+}$ appeared along with the doublet of $\mathrm{Fe}^{3+}$ proving that sulfur acted as a reducing agent for $\mathrm{Fe}^{3+}$. Glass sample doped with 5 wt \% sulfur exhibited higher conductivity and smaller activation energy than S-free samples. This is due to the presence of $\mathrm{Fe}^{2+}$ ions in addition to $\mathrm{Fe}^{3+}$ ions. HTsamples showed lower conductivity due to the blocking effect.

\section{REFERENCES}

[1] M. Yoshiyagawa, M. Tomozawa, J. Phys. Colloq. 1982, 43, 411.

[2] F. H. E. Batal, M. A. Azooz, Y. M. Hamdy, Ceram. Internat. 2009, 35, 1211.

[3] M. Y. Hassaan, M. M. El-Desoky, H. Masuda, S. Kubuki, T. Nishida, Hyperfine Interact. 2012, 205, 91.

[4] M. Y. Hassaan, S. M. Salem, M. G. Moustafa, J. NonCryst. Solids 2014, 391, 6.

[5] N. F. Mott, Adv. Phys. 1967, 16, 49.

[6] M. Wakihara, Mater. Sci. Eng. 2001, R.33, 109.

[7] G. X. Wang, B. Bewlay, J. Yao, Y. Chen, Z. P. Guo, H. K. Liu, S. X. Dou, J. Power Sources 2003, 119, 189.

[8] G. Sarre, P. Blanchard, M. Broussely, J. Power Sources 2004, 127, 65.

[9] S. M. Lee, Y. H. Kim, C. H. Song, S. J. Yoon, H. S. Kim, Y. S. Yang, J. Korean Phys. Soc. 2011, 58, 616.

[10] G. Wen, X. Zheng, L. Song, Acta Matter. 2007, 55, 3583.

[11] S. Furusawa, T. Kasahara, A. Kamiyama, Solid State Ion. 2009, 180, 649.

[12] G. K. Williamson, W. H. Hall, Acta Metall. 1953, 1, 22. 
[13] A. Burns, H. P. Brack, W. M. J. Risen, J. Non-Cryst. Solids 1991, 131-133, 994.

[14] R. S. Husung, R. H. Doremus, J. Mater. Res. 1990, 5, 2209.

[15] S. A. MacDonald, C. R. Schardt, D. J. Masiello, J. H. Simmons, J. Non-Cryst. Solids 2000, 275, 72.

[16] S. Ibrahim, M. M. Morsi, Mater. Chem. Phys. 2013, $138,628$.

[17] O. Tolstova, S. Stefanovsky, T. Lashtchenova, in: Proceedings of the 2nd Balkan Conference on Glass
Science and Technology: 14th Conference of Glass and Ceramics, Varna, 24-28 Sept., 2002.

[18] E. A. Hayri, M. Greenblatt, J. Non-Cryst. Solids 1987, 94, 387.

[19] I. G. Austin, N. F. Mott, Adv. Phys. 1969, 18, 41.

[20] M. Y. Hassaan, M. M. El-Desoky, S. M. Salem, S. H. Salah, J. Radioanal. Nucl. Chem. 2001, 249, 595.

[21] M. Kleitz, M. C. Steil, J. Eur. Ceram. Soc. 1997, 17, 819.

[22] M. M. El-Desoky, J. Non-Crst. Solids 2005, 35, 3139. 